By: Anne C. Fletcher, Glen H. Elder, Jr., and Debra Mekos

Fletcher, A. C., Elder, G. H., Jr., \& Mekos, D. (2000). Parental influences on adolescent involvement in community activities. Journal of Research on Adolescence, 10, 29-48.

Made available courtesy of Wiley-Blackwell: The definitive version is available at http://www3.interscience.wiley.com

****Reprinted with permission. No further reproduction is authorized without written permission from Wiley-Blackwell. This version of the document is not the version of record. Figures and/or pictures may be missing from this format of the document. $* * *$

\begin{abstract}
:
Youth involvement in extracurricular activities reflects both family socialization influences and civic development. Parents can promote such activity through examples set by personal involvement in the community and through reinforcement of their children's interests. Using data $(N=362)$ from the 9th and 10th grade waves of the Iowa Youth and Families Project (Conger \& Elder, 1994), we find that both the behavioral model set by parents and their personal reinforcement of children's actions make significant differences in the extracurricular activity involvement of boys and girls. However, parental reinforcement is most consequential when parents are not engaged in community activities. In this situation, warm parents are likely to reinforce their children, and this reinforcement strengthens children's involvement in community activities. The family dynamics of civic socialization deserve more attention than they have received to date.
\end{abstract}

\title{
Article:
}

American youth spend a substantial number of hours in extracurricular activities, including school-based clubs, school and local sports teams, and community-based organizations such as service clubs and church youth groups (Carnegie Council on Adolescent Development, 1992). A small but rapidly growing body of literature suggests that participation in both school- and community-based extracurricular activities is associated with and predictive of behavioral well-being among adolescents. hi particular, youth extracurricular involvement is frequently linked with academic competence. Adolescents' involvement in volunteer service or participation in church-sponsored activities is associated with better academic performance during high school and an increased likelihood of college attendance (Eccles \& Barber, 1999). Student participation in organized sports has been linked with higher academic grades, greater expressed liking of school during the high school years, and an increased likelihood of college attendance (Eccles \& Barber, 1999). Involvement in school-based extracurricular activities during adolescence appears to serve as a protective factor against early school leaving (Mahoney \& Cairns, 1997; McNeal, 1995). Participation in leadership activities and clubs and special interest groups is associated with students' achieving higher academic grades, and having greater school engagement and higher educational aspirations (Lamborn, Brown, Mounts, \& Steinberg, 1992). Less readily apparent benefits of civic participation include its potential to reinforce positive social values (Almond \& Verba, 1963; Youniss, McLellan, \& Yates, 1997) and set in motion a lifetime pattern of civic activity (Hanks \& Eckland, 1978). Youth involvement in service activities meets community needs and applies principles and values that chart a lifetime course of adult development.

Although the benefits of civic involvement to adolescents and communities are strong and far-reaching, such participation is not always without accompanying risks. Of particular concern are findings that adolescents who participate in organized sports activities, although benefitting academically from their involvement, may be at an increased risk for involvement in deviant behavior, and in particular higher levels of alcohol and drug use (Eccles \& Barber, 1999). In sum, it appears civic involvement in general benefits adolescents academically and socially, but participation in organized sports activities may place certain youth at risk of increased drug and alcohol use. 
Given that the balance of research evidence suggests overall benefits of extracurricular participation during adolescence, investigators are now beginning to ask what factors may increase the likelihood that individual adolescents will choose to participate in such activities. Given the important role parents play in linking children to the world around them (Parke \& Ladd, 1992), it is likely that children learn much about the value of civic involvement through the actions of their parents (Almond \& Verba, 1963). We know that children tend to resemble parents in expressed commitment to educational (Featherman, 1980; Natriello \& McDill, 1986) and religious (Acock, 1984; Cornwall, 1989) institutions. Research evidence using the same data set analyzed in this article has demonstrated that a good predictor of adolescents' own extracurricular participation is the community involvement of their parents (Chan \& Elder, 1999; Elder \& Conger, in press).

Theoretically, parents who believe in the value of civic participation, yet are prevented from acting on their beliefs, could find means other than their own examples to encourage children to take full advantage of community opportunities. In this article, we are interested in identifying ways in which parents might influence offspring extracurricular involvement that were conceptually distinct from parents' own levels of civic participation. To identify such potential parental influences, we referred to previous empirical research documenting linkages between parenting and child extracurricular involvement, to theoretical work distinguishing between stylistic versus behavioral aspects of parenting, and to the work of Bronfenbrenner (1977, 1986), emphasizing the importance of considering ecological contexts in which influences on child development occur.

The one study that has attempted to identify parental influences on child activity involvement (Csikszentmihalyi, Rathunde, \& Whalen, 1993) found that the participation of gifted youth in activities that support their talents is supported by parents who are warm and involved in their children's lives and who actively reinforce their children's activity participation. Interestingly, these two components, parental warmth and parental encouragement or reinforcement, fall into two conceptually distinct categories of parental influences. Warmth is typically considered a stylistic aspect of parenting. By contrast, parents who explicitly reinforce children to become involved in community activities are engaging in a type of parenting practice.

Parenting style is typically conceptualized as describing a general emotional climate within the home. This emotional climate depends on where parents fall on general dimensions of parental emphasis, such as warmth, behavioral control, or psychological autonomy granting, Warm and responsive parents may differ in the specific manners in which they interact with their children, but all wain parents share an underlying emphasis on concern for and responsiveness to children's specific needs. In contrast, parenting practices are the specific, goal-directed behaviors that parents exhibit with their children. The distinction between parenting styles and practices is significant (Darling \& Steinberg, 1993), and the manner in which the two work together can be complex. For example, authoritative parents (a parenting style that ranks high on warmth and limit-setting) are more likely to be involved in their adolescents' school experiences (a parenting practice). Parental involvement in adolescents' schooling typically has beneficial effects when it involves authoritative parents. However, it is associated with negative outcomes when it is exhibited by authoritarian parents who are low in warmth and high in limit-setting (Steinberg, Lamborn, Dornbusch, \& Darling, 1992). In short, parenting style serves as a moderator of associations between parental involvement in schooling and adolescent academic competence.

The same variable (in the previous example, parenting style) can both directly influence a given outcome variable and moderate associations between other predictor variables and said outcome (Baron \& Kenny, 1986). In the case of moderation, a variable of interest is considered to set a context under which patterns of association among other variables may vary. Accordingly, moderator-focused research questions allow attention to be focused on the often overlooked (Bronfenbrenner, 1977, 1986) role of ecological context in child development. Research questions involving moderating effects are theoretically driven and require different data analytic strategies than do questions concerning more direct linkages between variables.

Given research suggesting the importance of parental warmth as a stylistic dimension of parenting readily identified among parents and linked with a wide range of adaptive child outcomes (see Maccoby \& Martin, 
1983, for review), and empirical work suggesting its importance for the support of activity participation among gifted adolescents (Csikszentmihalyi et al., 1993), we decided to focus in this article on its role as a parental predictor of activity involvement in a more heterogeneous adolescent population. We also decided to focus on parental encouragement, or reinforcement, of activity participation as a parenting practice that would logically appear to increase the likelihood that adolescents will become involved in school- and community-based extracurricular activities.

Previous work with this same data set (Chan \& Elder, 1999; Elder \& Conger, in press) has demonstrated that parental involvement in community activities is predictive of adolescent civic participation. In keeping with theoretical and empirical emphases (Bronfenbrenner, 1977, 1986; Steinberg et al., 1992) on the importance of ecological context, we chose to examine the role of parental involvement in community activities as defining a context in which parenting styles and behaviors are expressed. Warm parents, who may or may not reinforce their children to participate in various activities, are exhibiting such behavior against a backdrop of their own civic participation or lack thereof. As noted, the civic involvement of parents depends on time-if parents work long hours, for example, they may not be able to put much time into the community. Reinforcement of youth opportunities and experiences may support the participational influence of parents, and it may underscore the importance of participation when parents are too busy to become involved in their communities. Accordingly, the functional meaning of parental reinforcement and warmth depends on the community roles of parents; parental community involvement potentially moderates effects of parental warmth and reinforcement on adolescent activity involvement. To understand the moderating role played by parental civic involvement, we can examine associations between adolescent activity involvement and other parental influences separately for groups of families defined by their levels of civic participation (Baron \& Kenny, 1986).

The warmth, reinforcement, and civic engagement of parents represent three different modes of intergenerational influence in the socialization of children's social involvement. This study investigates the role of these three distinct influences in determining the social involvement of youth. In theory, youth with warm parents are likely to be involved in community activities. A portion of this effect may be explained by the tendency of warm parents to reinforce their children in social endeavors. Both warmth and reinforcement should generate more of a difference in the social involvement of children when parents are relatively inactive. Data come from two waves of the Iowa Youth and Families Project.

\section{SAMPLE AND METHOD}

\section{Participants}

Participants were drawn from the Iowa Youth and Families Project (Conger \& Elder, 1994), a longitudinal study of 451 European American families from eight rural counties in north central Iowa. No minority families participated in this project because they resided in the target counties in such small numbers. Families were initially recruited for participation in 1989 if they had two biological parents living within the home, a seventh grade child, and a near-aged sibling. All participating families lived on farms or in rural communities with populations less than 6,500 (see Conger \& Elder, 1994, for more details on sample and data collection procedures). Participating families were heavily reliant on an agriculture economy, both as farmers and members of communities heavily invested in agricultural success. The years prior to and encompassing this project witnessed plummeting land values, rising unemployment, stalled economic development, and the closing of numerous community businesses throughout the Midwest, and these Iowa counties were hit particularly hard by the agriculture crisis of the 1980s.

Data used in this project are from the third and fourth waves of data collection, during which time participants were in the 9th and 10th grades. Only families who were still in intact marriages at this time yielded data for these analyses, resulting in an overall sample size of 362 families (target female participants $=190$, male participants $=172$ ) . 


\section{Procedure}

Researchers visited families in their homes on two occasions during each wave of data collection. During the first of these visits, parents, adolescents, and siblings completed a variety of questionnaires, Participants were also left an additional set of questionnaires to be completed and returned to researchers by mail. Questionnaires focused on a wide range of indexes of individual and family functioning and adjustment, as well as participants' daily activities and community integration. During the second visit, families participated in a series of videotaped structured interaction tasks that generated the measure of parental warmth described next.

\section{Measures}

Parental community involvement. When target adolescents were in 9th grade, each parent reported on whether he or she was involved in any community activities, the hours spent involved in these activities, leadership positions held, and church attendance. Activity involvement was determined by multiplying the number of reported community activities by hours of involvement for each parent (resulting mothers' component score: $\mathrm{M}=6.81, S D=7.27$, range $=0-50$; resulting fathers' component score: $\mathrm{M}=7.57, S D=8.81$, range $=0-60)$. Activity leadership was scored as a 0 if a parent held no community leadership positions and 1 if a parent held at least one leadership position (resulting mothers' component score: $\mathrm{M}=.41, S D=.49$, range $=$ $0-1$; resulting fathers' component score: $\mathrm{M}=.40, \mathrm{SD}=, 49$, range $=0-1$ ). Church attendance was scored as a 0 if parents attended church less than once a week, a 1 if parents attended church once a week, and a 2 if parents attended church more than once a week (resulting mothers' component score: $\mathrm{M}=.75, S D=.70$, range $=0-2$; resulting fathers' component score: $\mathrm{M}=.64, S D=71$, range $=0-2$ ). Each of the three components of parental community involvement was converted to $\mathrm{z}$ scores for mothers and for fathers, then summed across these three indexes. These overall measures of mothers' and fathers' community involvement were averaged to obtain a measure of parental community involvement (adapted from Elder \& Conger, in press).

Parental warmth. The measure of parental warmth was obtained from a structured interaction task administered to parent - adolescent dyads within their homes. Prior to beginning these tasks, the researcher visiting the home had family members individually complete questionnaires designed to identify issues that often led to disagreements within the family. Family members were then asked to discuss a series of issues. Prior to discussion of each issue, the researchers started video recording equipment and left the room, returning after a set period of time to introduce the next topic of discussion and round of videotaping. Some of the discussion topics were of general interest to families, including parenting approaches and assignment of household responsibilities. Three topics were selected based on each family's questionnaire identification of issues of concern for their particular family. In such cases, families were asked to discuss and resolve the issue that was the most conflictual for their family, and to discuss and resolve the two remaining issues in turn, if time allowed. Videotapes were subsequently coded by trained observers (graduate research assistants or college graduate hourly employees, all of whom had completed a 200-240-hr training program to learn observational coding techniques) for a variety of interactional qualities (Conger, Ge, Elder, Lorenz, \& Simons, 1994), including fathers' and mothers' warmth toward their children. Warmth was defined as expressions of care, concern, support, or encouragement exhibited by the parent toward the adolescent. Warmth scores ranged from 1 (low) to 5 (high). Intraclass correlations were initially calculated as a measure of observer agreement, and were relatively low (.43 for mothers, .33 for fathers). Accordingly, raters met and reconciled all rating differences. The measures of maternal and paternal warmth used in this analyses represent this "consensus coded" data, making it of higher quality than would be suggested by intraclass correlations. Scores were then averaged across adolescents' interactions with mothers and fathers to obtain an overall measure of parental warmth.

Parental reinforcement. Each parent completed the five-item reinforcement scale, designed to measure the extent to which the parent regularly demonstrated to the adolescent (in 9th grade) support for his or her activities, interests, and ideas $(\alpha=.75$ [fathers], .80 [mothers]; sample item: "How often do you let this child know that you appreciate him/her, his /her ideas or the things he/she does?"). Responses to individual items were scored on different scales, and were summed across items for each parent after standardization. The final 
measure of parental reinforcement was obtained by averaging across mother and father responses, with high scores indicating strong reinforcement of adolescents.

Adolescent involvement in community activities. During the 9th and 10th grades, adolescents reported their involvement in all school and community-based extracurricular activities. Adolescents were specifically questioned concerning involvement in school sports, whether they held any sports leadership positions (e.g., captain, cocaptain, or manager), participation in other school activities or offices (e.g., band, homecoming committee, science club), and involvement in community activities (e.g., Sunday-school teacher, Future Farmers of America, recreational basketball). Youth were assigned scores representing the total number of such activities in which they participated in 9th grade and again in 10th grade. The number of 9th grade activities reported by adolescents ranged from 0 to 14 for girls and from 0 to 13 for boys. Tenth grade activity involvement ranged from participation in 0 to 15 activities for boys and girls. Preliminary data analyses examined whether the effects documented in this article differed when we considered separately different types of activity participation (e.g., sports involvement, service activities, academic clubs). These analyses indicated that parental effects on such activity involvement did not differ according to activity type. Accordingly, we collapsed all types of activity participation into one composite measure. We also believed that extensive involvement with one type of extracurricular activity was not equivalent to involvement across a wide range of activities. Intense, focused participation with one specific group or sport may indicate a significant interest or talent, but not necessarily an equally strong level of community investment. This is particularly likely to be true in small, rural communities in which more students are likely to be included in extracurricular activities. In such environments, for example, tremendous athletic prowess is not necessarily a prerequisite for membership on the school football team. Membership on the football team in a small community is more likely to be an indicator of school or community involvement in general, and its benefits may accumulate with those of other types of activities, such as membership on the debate team or serving meals at the local homeless shelter.

\section{Plan of Analysis}

Using a traditional approach, questions regarding the roles of parental involvement in community activities, parental warmth, and parental encouragement in relation to adolescent activity involvement would be investigated by examining interaction effects to consider whether effects of specific parental variables (e.g., the influence of parental warmth) varied in relation to levels of other predictor variables (e.g., parental involvement in community activities). If significant interaction effects were observed, the sample would then be divided based on levels of parental community involvement to determine whether the effects of warmth on adolescent activity involvement varied for parents who were high versus low in involvement themselves.

In this case, this traditional approach is not warranted, for reasons having to do with statistical power and hypothesis testing. Rosnow and Rosenthal (1989a, 1989b) argued that the approach outlined previously is inappropriately conservative, as the power needed to detect significant interaction effects typically requires extremely large samples. Instead, these experts argued that researchers should perform focused tests based on theory-driven predictions concerning the nature of relations among variables.

To develop predictions concerning the nature of associations between parental variables and adolescent involvement in community activities, we drew on three sources. Darling and Steinberg (1993) stressed the importance of distinguishing between the roles of parenting style and parenting practices in child socialization research. The writings of Bronfenbrenner (1977, 1986), have stressed the importance of considering ecological context in developmental work. Finally, previous research using this same data set (Chan \& Elder, 1999; Elder \& Conger, in press) has demonstrated that a key factor associated with adolescent community involvement is the community involvement of parents.

Based on our readings of the previous works, we believed it likely that parental involvement in community activities represented a context that would moderate associations between other parental variables (parental warmth and encouragement) and adolescent involvement in community activities. Accordingly, we divided families into two groups based on a median split of parental community involvement. We then developed a 
model (Figure 1) predicting that parental warmth (a stylistic dimension of parenting style) contemporaneously influences adolescents' likelihood of participating in 9th grade extracurricular activities both directly and indirectly, by influencing parents' likelihood of encouraging their children's activities and interests (a parenting practice). Parental warmth and reinforcement are similarly presumed to influence adolescent involvement in extracurricular activities 1 year later, in 10th grade. Least squares regression techniques were used to determine path coefficients or beta weights (standardized partial regression coefficients) for a path analysis describing these relations. Path analysis is preferable to structural equation modeling when sample size is small and when conducting inductive analyses rather than testing a more complete theory than is represented by the model presented here (Biddle \& Marlin, 1987).

Preliminary analyses were conducted separately for boys versus girls to determine whether separate models should be tested for each.

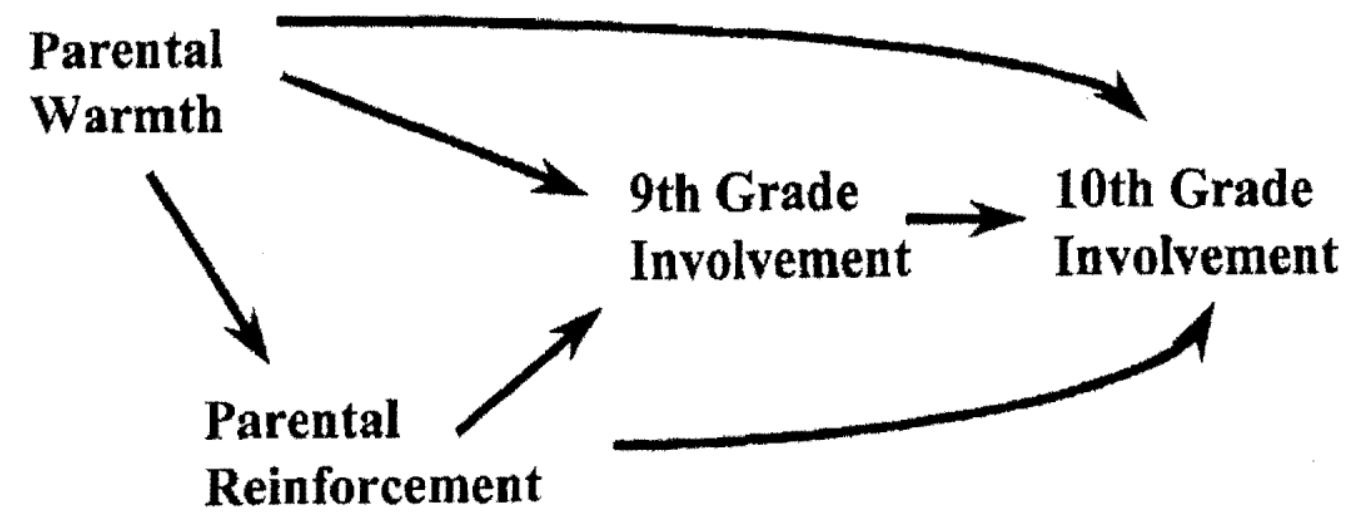

\section{RESULTS}

FIGURE 1 Model predicting adolescent activity involvement from parental warmth and reinforcement.

\section{Comparisons of Means for Boys Versus Girls}

Table 1 shows means and standard deviations for all model variables separately for boys and girls. In the 9th grade, girls participated in an average of 5,43 activities, whereas boys participated in an average of 4.33 activities, 0359.1) $=3.88, p<.01$. In 10th grade, girls were still participating in significantly more activities, 5.05 , than boys, $4.25, \mathrm{t}(360)=2.47, p<.05$, although the magnitude of this difference was somewhat smaller. No other means differed by sex.

TABLE 1

Means and Standard Deviations of Variables

\begin{tabular}{lccrrr}
\hline & \multicolumn{2}{c}{ Girls $^{a}$} & & \multicolumn{2}{c}{ Boys $^{b}$} \\
\cline { 3 - 6 } Variable & $M$ & $S D$ & & $M$ & $S D$ \\
\hline Parental community involvement & .01 & .66 & -.01 & .64 \\
Parental warmth & 2.34 & .79 & 2.42 & .72 \\
Parental reinforcement & .06 & 2.68 & .09 & 2.75 \\
9th grade involvement ${ }^{c}$ & 5.43 & 2.91 & 4.33 & 2.50 \\
10th grade involvement ${ }^{d}$ & 5.05 & 3.26 & 4.25 & 2.90 \\
\hline${ }^{a} n=190 .{ }^{b} n=172 .{ }^{c} p<.01$ for contrast between girls and boys. ${ }^{d} p<.05$ for contrast between \\
girls and boys.
\end{tabular}

\section{Correlations Among Model Variables}

Overall, correlations among variables were similar in direction and magnitude for boys and girls. Accordingly, we combined participants across sex. We performed a median split based on levels of parental community involvement within each family. All subsequent analyses were then performed separately for the high versus 
low parental involvement families. Table 2 presents correlations among model variables for these combined groups of boys and girls, but separating families high versus low in parental community involvement, Parental warmth and reinforcement are significantly associated for high- and low-involvement families. Among lowinvolvement families, both parental warmth and reinforcement are significantly associated with 9th grade adolescent community involvement and predictive of 10th grade community involvement. In contrast, among high-involvement families, 9th grade parental warmth and reinforcement are significantly associated with contemporaneous adolescent activity involvement, but not with adolescent activity involvement 1 year later. Within both groups, there are strong significant associations between 9th and 10th grade levels of activity involvement.

TABLE 2

The Interrelation of Parental Warmth, Reinforcement, and Adolescent Involvement for Involved and Uninvolved Parents

\begin{tabular}{lccccccccc}
\hline Variable & 1 & & 2 & & 3 & & 4 \\
\hline 1. Parental warmth & - & \multicolumn{2}{c}{$.27^{* *}$} & & $.17^{*}$ & & .14 \\
2. Parental reinforcement & $.20^{* *}$ & & - & & $.19^{*}$ & & .11 & \\
3. T1 adolescent involvement & $.21^{* *}$ & & $.19^{* *}$ & & - & & $.71^{* *}$ & \\
4. T2 adolescent involvement & $.26^{* *}$ & & $.32^{* *}$ & & $.66^{* *}$ & & - & \\
& $M$ & $S D$ & $M$ & $S D$ & $M$ & $S D$ & $M$ & $S D$ \\
Low-involvement families & 2.35 & .73 & -.05 & 2.80 & 4.31 & 2.77 & 3.88 & 2.70 \\
High-involvement families & 2.41 & .78 & .21 & 2.62 & $5.49^{* *}$ & 2.66 & $5.46^{* *}$ & 3.30
\end{tabular}

Note. Correlations for high community involvement families are above the diagonal; correlations for low community involvement families are below the diagonal. $\mathrm{T} 1=$ Time $1 ; \mathrm{T} 2=$ Time 2.

$* p<.05, * * p<.01$.

\section{Comparison of High-Versus Low-Involvement Families}

Table 2 also shows the means and standard deviations for all model variables separately for high versus low community involvement families. In 9th grade, adolescents from high-involvement families participated in an average of 5.49 activities, whereas adolescents from low-involvement families participated in an average of 4.31 activities, $\mathrm{t}(360)=4.13, \mathrm{p}<.01$. In 10th grade, adolescents from high-involvement families still participated in significantly more activities, 5.46, than adolescents from low-involvement families, 3.88, $\mathrm{t}(346.6)=4.96, p<.01$. No other variable means differed significantly for these two groups.

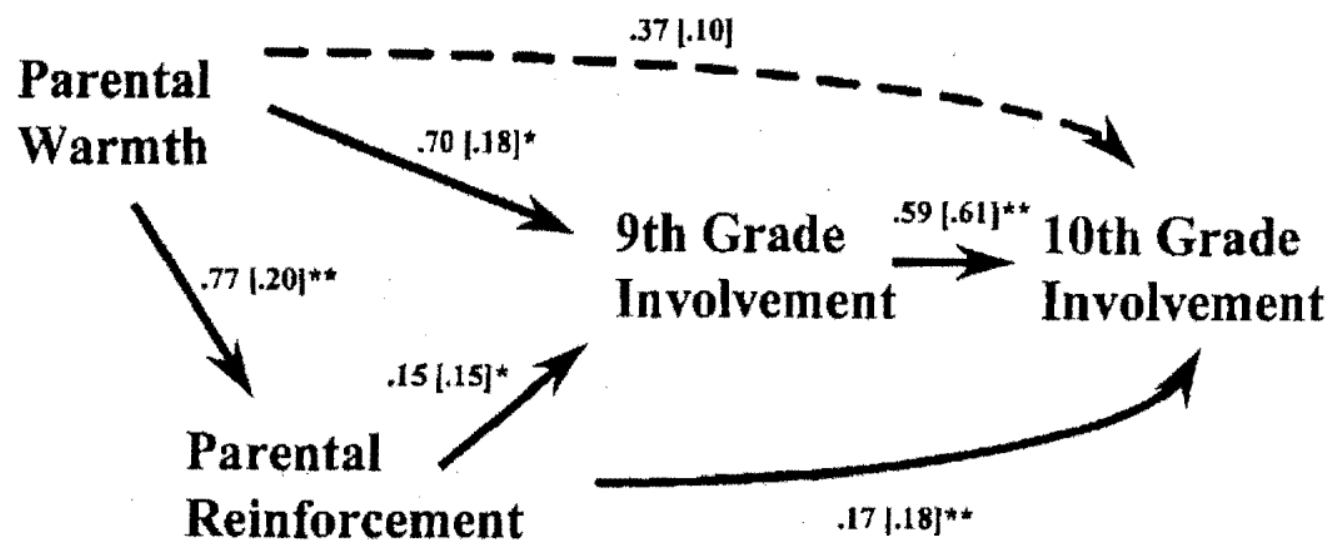

FIGURE 2 The social involvement of adolescents from low-involvement families as predicted by parental warmth and reinforcement. Unstandardized parameters are shown out of brackets, standardized parameters within brackets. Statistically significant paths are denoted with solid lines, nonsignificant paths with broken lines. ${ }^{*} p<.05$. ${ }^{* *} p<.01$. 


\section{Path Analyses}

Given the strong correlations observed among model variables, path analysis was an especially appropriate method of analysis, as it determine the unique contributions of each predictor of adolescent activity involvement, controlling for effects of other predictors. We performed path analyses separately for low versus high parental involvement families, predicting 9th and 10th grade activity involvement from 9th grade parental warmth and reinforcement. The results of the two path analyses are shown in Figures 2 and 3. To summarize, they indicate that among low-involvement families, 9th grade parental warmth and reinforcement are associated with $9^{\text {th }}$ grade youth activity involvement and predictive of Time 2 activity involvement. Among highinvolvement families, adolescent involvement is not predicted longitudinally by parental factors.

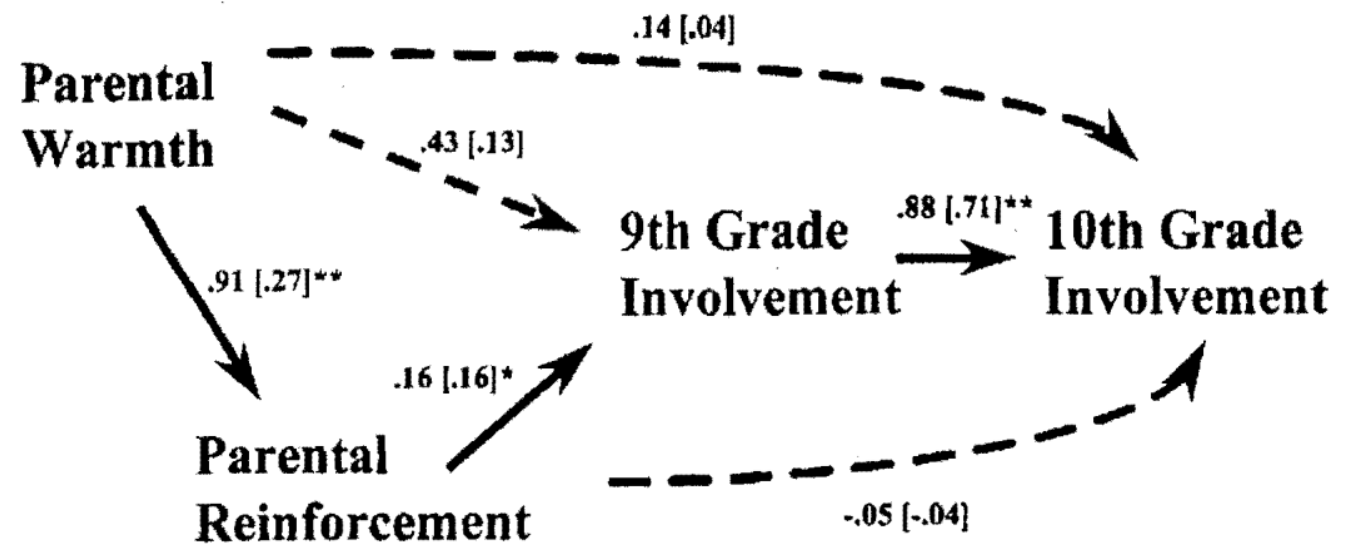

FIGURE 3 The social involvement of adolescents predicted by parental warmth and reinforcement in high-involvement families. Unstandardized parameters are shown out of brackets, standardized parameters within brackets. Statistically significant paths are dennted with solid lines, nonsignificant paths with broken lines. ${ }^{*} p<.05 .{ }^{* *} p<.01$.

Adolescents from low-involvement families. The model predicting 9th grade activity involvement for adolescents from families in which parents were less involved in community activities (Figure 2) was significant, $\mathrm{F}(2,174)=6.33, p<.01$. Parental warmth accounted for $3 \%$ of the variance and reinforcement accounted for $2 \%$ of the variance. The model predicting 10th grade activity involvement was also significant, $\mathrm{F}(3,173)=53.07, p<.01$. In this case, 9 th grade activity involvement accounted for $37 \%$ of the variance in 10th grade activity participation and 9th grade parental reinforcement accounted for an additional $3 \%$ of the variance in 10th grade activity participation over and above the contribution of 9 th grade participation. At a $p<$ .05 significance level, all predictor variables in the path diagram were significantly related to activity involvement outcomes, with the exception of 9th grade parental warmth, which was not predictive of 10th grade activity involvement once parental reinforcement was simultaneously included in the equation. When both 9 th grade parental warmth and 9th grade reinforcement were included in the prediction of 10th grade activity involvement, the previously observed significant bivariate correlation between 9th grade warmth and 10th grade involvement was reduced to below significance, indicating that parental reinforcement mediates the relation between 9th grade parental warmth and 10th grade youth activity involvement.

Adolescents from high-involvement families. Among youth from high parental involvement families (Figure 3 ), the model predicting 9th grade activity involvement was significant, $\mathrm{F}(2,176)=4.73, p<.05$. However, the association of warmth and activity involvement did not reach a $p<.05$ statistical significance level, Ninth grade parental reinforcement alone accounted for $2 \%$ of the variance in contemporaneous activity involvement. The model predicting 10th grade activity involvement was also significant, $\mathrm{F}(3,175)=58.28, p<.01$, but neither 9th grade parental warmth nor reinforcement was predictive of 10th grade activity involvement. Instead, 9th grade activity involvement accounted for $50 \%$ of the variance in 10th grade activity involvement. 


\section{Post Hoc Comparisons Across Groups}

To test whether the differences between pairs of regression weights within the low versus high parental involvement groups were significant, we computed $95 \%$ confidence intervals to see whether the $\mathrm{z}$ scores for low-involvement youths' regression weights fell within the confidence intervals calculated around the $\mathrm{z}$ scores for the high-involvement adolescents' corresponding regression weights. In three cases, the regression weights for low-involvement youths' fell outside the confidence intervals calculated for the high-involvement adolescents. Parental warmth and reinforcement are more strongly associated among adolescents from highinvolvement families. Ninth grade parental reinforcement is more predictive of 10th grade adolescent activity involvement among youth from low-involvement families than from their counterparts from high-involvement families. Youth from families in which parents are highly involved in their communities show greater stability from 9 th to 10 th grade in activity involvement.

\section{DISCUSSION}

Parental warmth and reinforcement play important roles in promoting youth participation in school- and community-based extracurricular activities. However, the extent of parents' own involvement within their communities moderates these effects. When parents are inactive, we find strong contemporaneous associations between both parental warmth and reinforcement, and adolescent activity involvement. In such cases, parental warmth in 9th grade also predicts 10th grade adolescent community involvement indirectly, through the increased likelihood that warm parents will reinforce their children's endeavors. In contrast, in families high in parental community involvement, parental warmth and reinforcement are contemporaneously associated with higher levels of 9th grade adolescent activity involvement, but there is no longitudinal effect of warmth or reinforcement on adolescent activity involvement.

Parental warmth and reinforcement are typically predictive of positive outcomes among adolescents. Parental warmth contributes to positive child outcomes both when assessed as an independent dimension (Janssens \& Gerris, 1992), and as a component dimension of more broadly defined parenting styles (Steinberg, 1990). The benefits of parental reinforcement, or encouragement, occur for outcomes such as academic achievement (Steinberg et a]., 1992) and college attendance (Carpenter \& Fleishman, 1987). This study indicates that warm and supportive parenting also supports the development of civic engagement among youth. Such engagement is in turn likely to have developmental benefits, and in particular has been linked to increased levels of academic competence (Eccles \& Barber, 1999; Mahoney \& Cairns, 1997).

The varying nature of observed influences of parental warmth and reinforcement on adolescent activity involvement underscore the importance of drawing distinctions between stylistic and behavioral aspects of parenting when investigating familial influences on child and adolescent well-being. Much of the reason warm parents have socially involved youth appears to be because such parents reinforce their offsprings' interests and activities. This finding is consistent with a literature suggesting that beneficial effects of parental warmth may be explained by the parenting practices exhibited by warm parents (Steinberg et al., 1992).

The most interesting finding presented here is the identification of circumstances under which parental warmth and reinforcement are not reliably linked with adolescent community involvement. Adolescents whose parents vary in their own civic engagement occupy separate ecological niches that have different implications for the effectiveness of other parental socialization influences. Adolescents with socially engaged parents are themselves more likely to become involved in community activities, and to maintain involvement over time. Yet they are not susceptible to influences of parental factors other than parental community involvement. Past research (Chan \& Elder, 1999) has suggested that children whose parents are highly involved in community activities have increased opportunities and motivations to become involved themselves. It may be that strong parental community involvement puts in place constraints on adolescents that make the attitudes and other behaviors of parents irrelevant. If a father plays a strong leadership role in the county 4- $\mathrm{H}$ and is an enthusiastic "local" 4-H leader as well, his children may not have the option of refusing to participate in 4-H activities. This may be the case even if the highly involved father maintains a cold and distant relationship with his child, and is explicitly critical of his or her efforts and accomplishments. A ceiling effect may also help to explain these 
findings. Adolescents whose own parents are highly involved in community activities participate in a very large number of community activities. Adolescents from these families may be participating in as many activities as is logistically possible, making the additional influences of parental warmth and reinforcement negligible. In contrast, adolescents whose own parents are relatively uninvolved in community activities have fewer opportunities to observe and model community service. An alternative route is needed to direct them toward activity involvement. One such route is through the establishment of warm and supportive parental relationships. Warm parents inculcate a general sense of social competence in their children (Janssens \& Gerris, 1992), and socially competent children may seek out the social relationships with others that accompany extracurricular involvement. Adolescents who are unable to model their own parents' involvement patterns may also benefit from explicit parental reinforcement indicating that attempts to try out for the school basketball team, for example, are supported at home.

Past research has clearly demonstrated the numerous benefits to adolescents and communities of youth participation in a broad range of formal community activities. This research has identified several meaningful ways in which parents influence the likelihood of children's becoming involved in community activities. First, parents can themselves become involved and invested in their communities. Children who realize their parents care enough about communities to spend time and energy maintaining them are likely to model such behaviors, However, for a variety of reasons, parents today may be unable or unwilling to volunteer their own time outside the home. Parents who form warm and supportive relationships with their offspring are more likely to engage in parenting practices that explicitly reinforce children's civic participation. Youth who know their activities are important to parents are themselves more likely to develop (and potentially maintain) such interests. These options may be particularly important for parents who are raising children in rural areas hard hit by the economic downturns of the 1980s. Residents within such communities have traditionally been strong in community involvement and investment, and are heavily reliant on one another. As the recent farm crisis has threatened the economic viability of a way of life, parents are increasingly reminded of the importance of inculcating a sense of civic responsibility in the minds of their children, Adolescents who form ties to their communities of residence are less likely to consider relocating to distant locations when formulating career and educational plans (Elder \& Conger, in press). Given the heavy out-migration from Midwestern farming communities in recent years (Elder \& Conger, in press), many adults are now realizing they must find ways to enhance the appeal of home communities. Individuals who choose to reside in rural areas are also heavily reliant on the physical and social support of friends and neighbors. When hard times hit, or even when prosperous times require more resources than are readily available within the family unit, rural residents must turn to others for advice, moral support, or assistance in completing chores and projects. The social bonds formed through involvement in community activities benefit residents by strengthening social ties that may be needed in future years.

The research reported here is not without its limitations, First, adolescents themselves reported on both their perceptions of parental reinforcement and their own levels of activity involvement. An extensive literature documents adolescents' abilities to accurately and reliably report on their own parents' behaviors (see Golden, 1969; Moscowitz \& Schwarz, 1982), and there is no reason to suspect adolescent bias in reporting on their involvement in school and community activities. Still, we cannot completely rule out the possibility that observed associations between parental reinforcement and adolescent activity involvement are due to common source variance. In any case, no source other than youth report provides complete information concerning which adolescents are involved in school and community activities. Our confidence in findings is strengthened by the inclusion of an observational measure of parental warmth and by the role of parental reinforcement, which appears to link parental warmth and adolescent activity involvement.

We also recognize that it is of interest to know whether parental involvement in community activities moderates associations between stylistic and observable aspects of parenting and adolescent community involvement in single-parent families, families from other ethnic groups, and families living in contexts far removed from the rural Midwest. Unfortunately, the demographic composition of the counties most affected by the farm crisis of the 1980s precluded exploration of issues related to family structure and ethnicity. Future research efforts, 
directed toward populations in different areas of the country, should be able to establish whether the relations among parental context, style, and practice hold within more diverse communities. In addition, there may be other contextual factors that moderate associations between parenting styles and practices and the likelihood that adolescents will become involved and invested in their communities of residence. Such factors may include involvement levels of peers, community norms and expectations, and characteristics of schools. Future research endeavors would do well to consider these issues, and to identify contexts that support adolescent integration into community institutions.

Socialization researchers have long concluded that the actions and attitudes expressed by parents are potent influences on what children will become as adults. This article offers evidence suggesting that such socialization effects extend to the realm of civic responsibility, and that parents play a meaningful role in determining whether their offspring will invest in the social institutions of their communities. More important, we have shown that different types of influences from within the home can all serve similar functions in guiding youth toward a common endpoint - that of civic participation.. This finding suggests that as scholars and practitioners, we must be broad in our appreciation of the complexity of paths that may converge on a common goal. Each family must determine its own strengths and how to best focus them on the desired endpoint of raising children with an appreciation for civic responsibility.

\section{REFERENCES}

Acock, A. C. (1984). Parents and their children: The study of intergenerational influence. Sociology and Social Research, 68,151-171.

Almond, G. A., \& Verba, S. (1963). The civic culture: Political attitudes and democracy in five nations. Boston: Little, Brown,

Baron, K, \& Kenny, D. (1986). The moderator-mediator variable distinction in social psychological research: Conceptual, strategic, and statistical considerations. Journal of Personality and Social Psychology, 51,11731182.

Biddle, B., \& Marlin, M. (1987). Causality, confirmation, credulity, and structural equation modeling. Child Development, 58, 4-17.

Bronfenbrenner, U. (1977, July). Toward an experimental ecology of human development. American Psychologist, 32,513-531.

Bronfenbrenner, U. (1986). Ecology of the family as a context for human development: Research perspectives. Developmental Psychology, 22,723-742.

Carnegie Council on Adolescent Development. (1992). A matter of time: Risk and opportunity in the nonschool hours, New York: Task Force on Youth Development and Community Programs.

Carpenter, P. G, \& Fleishman, J. A. (1987). Linking intentions and behavior: Australian students' college plans and college attendance. American Educational Research Journal, 24, 79-105.

Chan, C. G., \& Elder, G, H., Jr. (1999). Family influences on civic involvement. Manuscript submitted for publication.

Conger, R. D., \& Elder, G. H., Jr., in collaboration with F. 0. Lorenz, R. L. Simons, \& L. B. Whitbeck. (1994). Families in troubled times: Adapting to change in rural America. New York: de Gruyter.

Conger, R. D., Ge, X., Elder, G. H. Jr., Lorenz, F. 0., \& Simons, R. L. (1994). Economic stress, coercive family process, and developmental problems of adolescents. Child Development, 65, 541-561,

Cornwall, M. (1989). The determinants of religious behavior: A theoretical model and empirical test. Social

Forces, 68, 572-592.

Csikszentrnihalyi, M., Rathunde, K., \& Whalen, S. (1993). Talented Teenagers: The Roots of Success and

Failure. New York: Cambridge University Press.

Darling, N., \&Steinberg, L, (1993). Parenting style as context: An integrative model. Psychological Bulletin, 173,487-196.

Eccles, J. S., Sr Barber, B. (1999). Student council, volunteering, basketball, or marching band: What kind of extracurricular involvement matters? Journal of Adolescent Research, 14,10-34.

Elder, C. H., Jr., \& Conger, R. D (in press). Children of the land: Adversity and success in rural America. Chicago: University of Chicago Press. 
Featherman, D. (1980), Schooling and occupational careers: Constancy and change in worldly success. In 0. Brim, Jr., \& J. Kagan (Eds.), Constancy and change in human development (pp. 675-738). Cambridge, MA: Harvard University Press.

Go)den, P. (1969). A review of children's reports of parental behaviors. Psychological Bulletin, 72:222-Z35. Hanks, M., \& Eckland, B. K. (1978). Adult voluntary associations and adolescent socialization. The Sociological Quarterly, 19,481-490.

Janssens, J. M. A. M., \& Gerris, J. R. M. (1992). Child rearing, empathy and prosocial development. In J. M. A, M. Janssens \& J. R. M Gerris (Eds,), Child rearing: Influence on prosocial and moral development (pp. 57-75). Amsterdam: Swets Sr Zeitlinger.

Lamborn, S. D., Brown, B. B., Mounts, NI. S., 8r Steinberg, L. (1992). Putting school in perspective: The influence of family, peers, extracurricular participation, and part-time work on academic engagement. In F. M. Newman (Ed.), Student engagement and achievement in American secondary schools (pp. 153-191). New York: Teachers College Press.

Maccoby, E., St Martin, J. (1983). Socialization in the context of the family: Parent-child interaction. In E. M. Hetherington (Ed.), Handbook of child psychology: Vol, 4, Socialization, personality, and social development (pp. 1-101). New York: Wiley.

Mahoney, J. L., \& Cairns, R. B. (1997). Do extracurricular activities protect against early school dropout? Developmental Psychology, 33,241-253.

McNeal, R. B. (1995). Extracurricular activities and high school dropouts. Sociology of Education, 68, 62-81. Moscow itz, D., dz Schwarz, J. (1982). A validity comparison of behavior counts and ratings by knowledgeable informants. Journal of Personality and Social Psychology, 42, 518-528. Natriello, G., \& McDill, E. (1986). Performance standards', student effort on homework, and academic achievement. Sociology of Education, 59, 18-31, Parke, R. D., \& Ladd, G. W. (1992). Family-peer relationships: Modes of linkage. Hillsdale, NJ: Lawrence Erlbaum Associates, Inc.

Rosnow, R. L., \& Rosenthal, R. (1989a). Definition and interpretation of interaction effects. Psychological Bulletin, 105, 143-146.

Rosnow, R. L., \& Rosenthal, R. (1989b). Statistical procedures and the justification of knowledge. in psychological science, American Psychologist, 44,1276-1284.

Steinberg, L. (1990). Interdependency in the family: Autonomy, conflict, and harmony. In S. Feldman \& G. Elliot (Eds.) At the threshold: The developing adolescent (pp. 255-276). Cambridge, MA: Harvard University Press.

Steinberg, L., Lamborn, S., Dombusch, S., \& Darling, N. (1992). Impact of parenting practices on adolescent achievement: Authoritative parenting, school involvement, and reinforcement to succeed. Child Development, 63,1266-1281.

Youniss, I., McLellan, J, A., \& Yates, M. (1997). What we know about engendering civic identity. American Behavioral Scientist, 40, 620-631. 